\title{
A Micropuncture Study of Renal Salt and Water Retention in Chronic Bile Duct Obstruction
}

\author{
Norman Bank and Hagop S. Aynedjian \\ From the Renal Division, Department of Medicine, Montefiore Hospital and \\ Medical Center and the Albert Einstein College of Medicine, \\ Bronx, New York 10467
}

A B S T R A C T The mechanism of sodium retention by the kidney in rats with ligation of the common bile duct was studied with micropuncture techniques. 10-14 days after bile duct ligation, rats showed positive sodium balance and ascites formation. Measurements of renal blood flow and glomerular filtration rate yielded values that were not different from those in normal control animals. Likewise, single nephron filtration rate of surface nephrons was the same in the experimental rats as in the controls. Sodium reabsorption, however, was markedly increased in the proximal convoluted tubule, as well as in segments beyond the proximal convolutions. Single nephron filtration fraction, calculated from measurements of efferent arteriolar and arterial hematocrits, was significantly elevated in the cortical nephrons, even though whole kidney filtration fraction was the same as in normal rats. The calculated protein concentration of cortical peritubular blood was higher in the bile duct-ligated rats than in the normal controls. The observations are consistent with the view that sodium retention is the result of enhanced reabsorption primarily by cortical nephrons. The enhanced reabsorption can be accounted for by relative cortical ischemia due to efferent arteriolar vasoconstriction with the consequent elevation of peritubular colloid oncotic pressure.

\section{INTRODUCTION}

Previous studies in dogs have shown that ligation of the common bile duct leads to sodium and water retention by the kidney and ascites formation (1-3). Although the mechanism of the abnormal renal function was not clear, this animal model was shown to bear several close similarities to human pathophysiology observed in patients with liver disease. Thus, patients with cirrhosis of the liver may demonstrate enhanced renal reabsorption of sodium, delayed excretion of a water

Received for publication 16 October 1974 and in revised form 30 December 1974. load, ascites, edema, and impaired urinary concentrating ability (4-8). Similar abnormalities were demonstrated in clearance studies in dogs with common bile duct ligation (3). In this latter study, the authors found that glomerular filtration rate $(G F R)^{1}$ and effective renal plasma flow ( $\mathrm{C}_{\mathrm{PAB}}$ ) were not altered by chronic bile duct ligation, and that the enhanced reabsorption of sodium occurred in the proximal and diluting segments of the nephron.

The present micropuncture study in rats was undertaken to further delineate the renal functional disturbances in chronic bile duct obstruction. Rats were studied 10-14 days after ligation of the common bile duct. Balance studies demonstrated sodium retention, and ascites was present at the time of micropuncture surgery. It was found that fractional and absolute sodium and water reabsorption are markedly increased in the proximal convoluted tubule. Single nephron filtration rate (SNGFR), as well as whole kidney GFR, were normal. However, single nephron blood flow (SNBF) of superficial nephrons was significantly reduced, and single nephron filtration fraction (SNFF) was significantly increased, while whole kidney measurements of these parameters of renal function were no different than in normal control rats. The calculated protein concentration in efferent arteriolar blood of superficial nephrons was higher in the experimental animals than in the controls. The ob-

\footnotetext{
${ }^{1}$ Abbreviations used in this paper: $\mathrm{A}_{\mathrm{In}}$, concentration of inulin in the arterial blood; $\mathrm{C}_{\mathbf{H} 20}$, free-water clearance; $\mathrm{C}_{\mathrm{PAH}}$, effective renal plasma flow; $\mathrm{FF}$, filtration fraction; GFR, glomerular filtration rate; $\mathrm{Hct}_{\mathbf{A}}$, arterial hematocrit; Hcte, hematocrit of the efferent arteriolar blood; RBF, renal blood flow; $R V_{I n}$, concentration in renal vein blood; SNBF, single nephron blood flow; SNFF, single nephron filtration fraction; SNGFR, single nephron filtration rate; $\mathrm{T}^{\mathrm{C}} \mathrm{H}_{2} \mathrm{O}$, free-water reabsorption; $\mathrm{TF} / \mathrm{P}_{\mathrm{In}}$, ratio of inulin in tubular fluid to that in plasma; TFR, tubular fluid flow rate in nanoliters per minute; $U_{\max }$, maximum urinary concentration; $U / P_{I n}$, ratio of inulin concentration in urine and plasma.
} 
servations suggest that sodium retention is the result of enhanced reabsorption primarily by cortical nephrons, and that this is caused by increased colloid oncotic pressure in the peritubular capillaries.

\section{METHODS}

White, male Sprague-Dawley rats, weighing 200-300 g, were maintained in individual metabolic cages. Except for those animals in which balance studies were carried out, described below, they were fed a regular rat pellet diet until $18 \mathrm{~h}$ before micropuncture study and were allowed tap water ad lib. In nine rats, anesthetized with i.p. Inactin, 10 $\mathrm{mg} / 100 \mathrm{~g}$, the common bile duct was doubly ligated with silk thread. They were returned to their cages for a period of 10-14 days, at the end of which time micropuncture studies were performed. Six rats, maintained on the same diet and water, served as the control group.

On the day of the micropuncture study, anesthesia was produced with i.p. Inactin, $10 \mathrm{mg} / 100 \mathrm{~g}$. A jugular vein was cannulated with $\mathrm{PE} 50$ polyethylene tubing for administration of Ringer's lactate solution at a constant rate of 0.05 $\mathrm{ml} / \mathrm{min}$. $d$-Aldosterone (Ciba Pharmaceutical Corp., Summit, N. J.) was added to the infusion to deliver $20 \mu \mathrm{g} / \mathrm{kg}$ body weight per h. [Carboxy- ${ }^{14} \mathrm{C}$ ] Inulin (New England Nuclear, Boston, Mass.) was given i.v. in a priming dose of $25 \mu \mathrm{Ci}$ and was administered continuously in the infusion at a rate of $25 \mu \mathrm{Ci} / \mathrm{h}$. A second $\mathrm{PE} 50$ tubing was inserted into the same jugular vein for injection of FD \& $C$ green no. 3 dye (Keystone Aniline \& Chemical Co., Chicago, Ill.). A carotid artery was cannulated with heparinized PE 50 tubing connected to a Statham strain gauge (model P 23 Dc, Statham Instruments, Inc., Oxnard, Calif.) for continuous recording of blood pressure by a Grass polygraph, model 5D (Grass Instrument Co., Quincy, Mass.). A volume of Ringer's lactate solution equal to $1 \%$ body weight was given i.v. over a 2-3-min period.

The left kidney was exposed through a small lateral abdominal incision. In the case of the bile duct-ligated animals, an increased amount of abdominal fluid was present, ranging from 5 to $25 \mathrm{ml}$. Strict precautions were taken during the abdominal surgery and throughout the experiment to prevent loss of this fluid. To accomplish this, the animal was placed right side down on the table during abdominal surgery, and after the left kidney was dissected free of perirenal adipose tissue, the skin was closed around the renal pedicle and the wound packed with silicone grease (Dow Corning Corp., Midland, Mich.). Upon completion of the surgery, the animal was repositioned on its back. The same surgical technique was carried out in two of the six normal rats to determine whether the special procedures altered renal function. The results were indistinguishable from the data in the four rats prepared in the usual fashion (9), and therefore all of the data for the normal rats are shown together. The exposed kidney was placed in a Lucite cup and immobilized with cotton. Mineral oil warmed to $38^{\circ} \mathrm{C}$ flowed continuously over the kidney. A fiber optic light system was used to illuminate the kidney surface. A PE 50 catheter was inserted into the exposed urinary bladder and tied in a manner which occluded bladder dead space. Body temperature was monitored continuously via a rectal thermistor and a telethermometer (Yellow Springs Instrument Company Inc., Yellow Springs, Ohio) and was maintained between $37-38^{\circ} \mathrm{C}$ by adjusting the heating mechanism of the animal table. An arterial blood sample was collected from the carotid cannula at the beginning of the experiment for measurement of hematocrit and total protein concentration. Subsequently, during tubular fluid collections, arterialized blood was collected from the cut end of the tail in heparinized capillary tubes at approximately $20-30-\mathrm{min}$ intervals for inulin measurement. After tubular fluid collections had been completed, a blood sample was collected slowly from the left renal vein, using a 25-gauge needle, for determination of inulin. In five of the control and five of the experimental rats, samples of blood were then collected from surface efferent arterioles (videinfra). During this part of the experiment, arterial blood was collected from the carotid artery at 20-min intervals for measurement of hematocrit and total protein. A final blood sample was obtained from the aorta and the left renal vein for measurement of inulin. Timed urine collections were obtained from the bladder catheter throughout the experiment.

Tubular fluid collections were obtained from the last convolution of proximal tubules visible on the surface of the kidney, by techniques previously described $(9,10)$. These convolutions were identified by their proximity to vascular "stars", by i.v. injection of $0.05 \mathrm{ml}$ of $10 \% \mathrm{FD} \&$ $\mathrm{C}$ dye, and by observing that injected oil droplets disappeared from the surface of the kidney, and did not reappear in any other surface convolutions. A long column. of castor oil colored with Sudan black was then injected into the tubular lumen with a micropipette and allowed to flow distally. The collection of tubular fluid was then started and timed with a stopwatch. The collection was made at a rate that maintained the oil block in place by adjusting the level of a mercury bulb connected to the micropipette. At the end of the collection, which usually lasted 4-6 min, the pipette was withdrawn from the lumen and its tip sealed by drawing in mineral oil from the surface of the kidney. Four to six tubular fluid collections were obtained in each rat.

In 10 rats, 5 control and 5 experimental, after the tubular fluid collections had been completed blood was collected from the central arteriole of vascular stars. In most instances, stars immediately adjacent to end-proximal convolutions which had been sampled for tubular fluid were chosen for puncture. Sharply ground siliconized and heparinized micropipettes, prepared before the day of the experiment and allowed to dry at room temperature, were inserted into these vessels under $\times 150$ magnification at an angle of approximately $70^{\circ}$ to the surface of the kidney. The tip of the micropipette was centered in the vessel so that none of its branches were occluded, and blood was allowed to flow freely into the pipette under its own pressure. At the end of the blood collection, the tip of the pipette was withdrawn and sealed by drawing in mineral oil from the surface of the kidney. Because the arterioles usually continued to bleed, obscuring the surface of the kidney, only two to four vessels could be punctured in each animal.

At the end of the experiment, the tubular fluid samples and portions of urine, tail plasma, and renal vein plasma were transferred to a constant-bore capillary tube, $0.1-\mathrm{mm}$ ID, for measurement of volume (11). They were then washed out of the capillary tube into liquid scintillation vials for radioactive counting in a Nuclear-Chicago liquid scintillation counter (Nuclear-Chicago Corp., Des Plaines, I11.). Plasma inulin concentration was corrected for a plasma water content of $94 \%$. The efferent arteriolar blood samples were transferred to a $0.1-\mathrm{mm}$ ID constant bore capillary tube which had previously been siliconized and which contained a column of mineral oil. The blood sample split the oil column, thereby providing an oil seal at each end of the column of blood. One end of the capillary tube was then heat-sealed over a microflame. It was then inserted 
TABLE I

Sodium Balance in Rats before and after Ligation of the Common Bile Duct*

\begin{tabular}{ccc}
\hline & \multicolumn{2}{c}{ Sodium recovered in urine } \\
\cline { 2 - 3 } Rat no. & Before & After \\
\hline & $\%$ & $\%$ \\
1 & 95.1 & 81.3 \\
2 & 94.2 & 94.8 \\
3 & 92.3 & 86.3 \\
4 & 92.7 & 85.5 \\
5 & 92.7 & 78.7 \\
6 & 91.9 & 86.9 \\
Mean & 93.2 & 85.6 \\
\hline
\end{tabular}

* Sodium intake was $1.875 \mathrm{meq} / \mathrm{day}$.

into a microhematocrit tube, one end of which had been heat-sealed, and centrifuged for $15 \mathrm{~min}$ in an International microhematocrit centrifuge (model CL, International Equipment Co., Boston, Mass.). The hematocrit of these samples was determined by measuring the total length of the sample and that of the packed erythrocytes under microscopic visualization, using an eyepiece micrometer. The hematocrit of arterial blood was measured in commercial microhematocrit tubes, using the same centrifuge. These samples were read on a Clay-Adams Microhematocrit reader, Clay-Adams, Inc., Parsippany, N. J. (A-2970). In preliminary tests, the hematocrit of arterial blood was measured by the ultramicro-method by drawing a portion of the sample into a collecting micropipette and then transferring it to the 0.1mm ID capillary tubing. Simultaneous measurements by this method and the larger volume micro-technique yielded results which were not significantly different from one another.

The following calculations were carried out from the inulin and hematocrit measurements.

$$
\mathrm{GFR}=\mathrm{U} / \mathrm{P}_{\mathrm{In}} \times \mathrm{V},
$$

where $U / P_{I n}$ is the ratio of inulin concentration in urine and plasma, and $\mathrm{V}$ is the urine flow rate in milliliters per minute. The plasma inulin concentration at the midpoint of the urine collection was determined from a plot of the plasma inulin concentrations vs. time. Since urine was collected from the bladder, the flow rate was halved to calculate the GFR of one kidney.

Filtration fraction (FF)

$$
\left.=\left[A_{I n}-R V_{\text {In }}\right) / A_{I n}\right] \times 100,
$$

where $A_{\text {In }}$ is the concentration of inulin in the arterial blood, and $R V_{I n}$ is the concentration in renal vein blood. The two samples needed for this calculation were collected within $1 \mathrm{~min}$ of each other.

$$
\text { Renal blood flow }(\mathrm{RBF})=\frac{\mathrm{GFR} / \mathrm{FF}}{1-\mathrm{Hct}_{\mathrm{A}}},
$$

where $\mathrm{Hct}_{\mathbf{A}}$ is the arterial hematocrit.

$$
\mathrm{SNGFR}=\mathrm{TF} / \mathrm{P}_{\mathrm{In}} \times \mathrm{TFR},
$$

where $T F / P_{1 n}$ is the ratio of inulin in tubular fluid to that in plasma, and TFR is the tubular fluid flow rate in nanoliters per minute.

$$
\begin{array}{r}
\mathrm{SNFF}=1-\left[\operatorname{Hct}_{\mathbf{A}}\left(1-\operatorname{Hct}_{\mathbf{E}}\right) /\right. \\
\left.\operatorname{Hct}_{\mathbf{E}}\left(1-\operatorname{Hct}_{\mathbf{A}}\right)\right] \times 100,
\end{array}
$$

where $\mathrm{Hct}_{\mathrm{w}}$ is the hematocrit of the efferent arteriolar blood.

$$
\mathrm{SNBF}=\frac{\mathrm{SNGFR} / \mathrm{SNFF}}{1-\mathrm{Hct}_{\mathbf{A}}} \text {. }
$$

The tubular fluid and efferent blood collections necessary for this calculation were made from adjacent structures.

Efferent protein concentration

$$
=\text { Protein }_{\mathbf{A}} / 1-\mathrm{SNFF} \text {. }
$$

In a separate group of experiments, sodium balance was measured in six rats before and after ligation of the common bile duct. The rats were kept in individual metabolic cages, were fed a sodium-free pellet diet (Nutritional Biochemicals, Cleveland, Ohio), and were given $25 \mathrm{ml}$ of 75 meq/liter $\mathrm{NaCl}$ solution to drink daily in a graduated Jshaped drinking tube. Since each rat consumed the entire $25 \mathrm{ml}$ each day, they received $1.875 \mathrm{meq} \mathrm{Na}^{+}$per day. After they finished their ration of saline, they were allowed tap water ad lib. for the rest of the day. They were maintained on this regimen for 5 days, after which 24 -h urine collections were obtained for 3 consecutive days. After this study, each rat underwent ligation of the common bile duct, as described above, and was returned to its cage. They were maintained on the same diet and drinking solution for an additional 10 days, after which 24 -h urine collections were obtained for 3 consecutive days.

Urinary sodium and potassium concentrations in the clearance and balance studies were measured with an Instrumentation Laboratory flame photometer, model 143 (Instrumentation Laboratory, Inc., Watertown, Mass.). Plasma protein was measured by the method of Reinhold (12). Paper electrophoresis was carried out on plasma proteins from four experimental and four control rats.

\section{RESULTS}

The results of sodium balance measurements in six rats before and after ligation of the common bile duct are shown in Table I. Before surgery, an average of $93.2 \%$ of the ingested sodium was recovered in the urine over a 3-day period of observation. The remainder of the sodium presumably was excreted in the feces or was lost due to technical reasons. 10-13 days after bile duct ligation, only $85.6 \%$ of the ingested sodium was recovered in the urine. This difference of $7.6 \%$ represents a positive sodium balance of approximately $142 \mu \mathrm{eq} /$ day. Thus, chronic common bile duct ligation in the rat, as in the dog (1-3), results in sodium retention by the kidney.

In Table II are summarized the renal clearance and hemodynamic data for the animals in which micropuncture studies were carried out. In contrast to the 3-day balance studies, sodium excretion during micropuncture experiments was not significantly different between the normal and bile duct-ligated rats. Although 
TABLE II

Renal Clearance and Hemodynamics in Normal and Bile Duct-Ligated Rats*

\begin{tabular}{|c|c|c|c|c|c|c|c|}
\hline & $\mathbf{V}$ & $\mathrm{UNaV}_{\mathrm{Na}}$ & $\mathrm{UK}_{\mathbf{K}} \mathrm{V}$ & GFR & RBF & FF & $\mathrm{U} / \mathrm{P}_{\mathrm{I}_{\mathrm{r}}}$ \\
\hline & $\mu l / \min / k g$ & $\mu e q / \min / \mathrm{kg}$ & $\mu e q / \min / \mathrm{kg}$ & $\mathrm{ml} / \mathrm{min} / \mathrm{kg}$ & $\mathrm{ml} / \mathrm{min} / \mathrm{kg}$ & $\%$ & \\
\hline \multicolumn{8}{|c|}{ Normal rats $(6) \ddagger$} \\
\hline Mean & 23.4 & 0.85 & 2.24 & 4.50 & 18.7 & 31.8 & 232 \\
\hline$\pm \mathrm{SE}$ & 0.7 & 0.47 & 0.59 & 0.53 & 2.1 & 2.0 & 61 \\
\hline \multicolumn{8}{|c|}{ Experimental rats (9) } \\
\hline Mean & 16.5 & 0.79 & 2.32 & 4.70 & 15.3 & 32.5 & 320 \\
\hline$\pm \mathrm{SE}$ & 3.1 & 0.18 & 0.54 & 0.30 & 1.9 & 2.0 & 38 \\
\hline$P$ & NS & NS & NS & NS & NS & NS & NS \\
\hline
\end{tabular}

* Data are for one kidney.

$\ddagger$ Numbers in parentheses are the number of rats.

Abbreviations: $\mathrm{U}_{\mathrm{Na}} \mathrm{V}=$ sodium excretion rate; $\mathrm{U}_{\mathbf{K}} \mathrm{V}=$ potassium excretion rate.

the reason for this is uncertain, we assume that differences in urinary excretion observed over a 24-h period in conscious animals may be difficult to detect in relatively short urine collections obtained during acute studies in anesthetized animals. That the bile ductligated rats used in the micropuncture studies had been in a sodium-retaining state was indicated by the presence of significant ascites in every animal. As can be seen from the table, there were no significant differences in GFR, RBF, or FF between the two groups. This is in agreement with the findings of Better and Massry (3) in bile duct-ligated dogs.

The average hematocrit for the control animals was $48.4 \% \pm 0.4 \mathrm{SE}$, and for the experimental animals was $42.0 \% \pm 0.5 \mathrm{SE}$. This difference is highly significant $(P<0.001)$. Powell, Dunnicliff, and Billing (13) have found that common bile duct ligation in the rat leads to shortening of erythrocyte survival and anemia, the effect being due presumably to elevated levels of conjugated bilirubin in the plasma. The mean plasma protein concentration in the control rats was $4.55 \mathrm{~g} / 100 \mathrm{ml} \pm 0.15$ $\mathrm{SE}$, and in the experimental rats was $4.62 \mathrm{~g} / 100 \mathrm{ml} \pm$ $0.18 \mathrm{SE}$. The mean value in the control rats is in agreement with that reported by Weinman, Kashgarian, and Hayslett (14). The percent of total protein present as albumin was $42.5 \%$ in the control rats and was $38.2 \%$ in the experimental rats.

The micropuncture findings are presented in Figs. 1 and 2 and are summarized in Table III. Fig. 1 shows the $T F / P_{\text {In }}$ values and tubular fluid flow rates collected from the last accessible proximal convolutions on the surface of the kidney. As can be seen, TF/ $\mathrm{P}_{\mathrm{In}}$ was significantly higher in the bile duct-ligated rats than in the controls, and TFR was significantly reduced. Although there was considerable overlap in $\mathrm{TF} / \mathrm{P}_{\text {In }}$ values, ratios of 4.0 and higher, as were observed in the experimental rats, are strikingly abnormal in our experience (15).
Expressed in terms of percent of glomerular filtrate reabsorbed, an average of $63 \%$ was absorbed by the surface proximal tubule in the normal rats and $75 \%$ in the experimental rats.

$T F / P_{\text {In }}$ were also measured in seven distal tubules of the experimental rats, without localization of the punc-

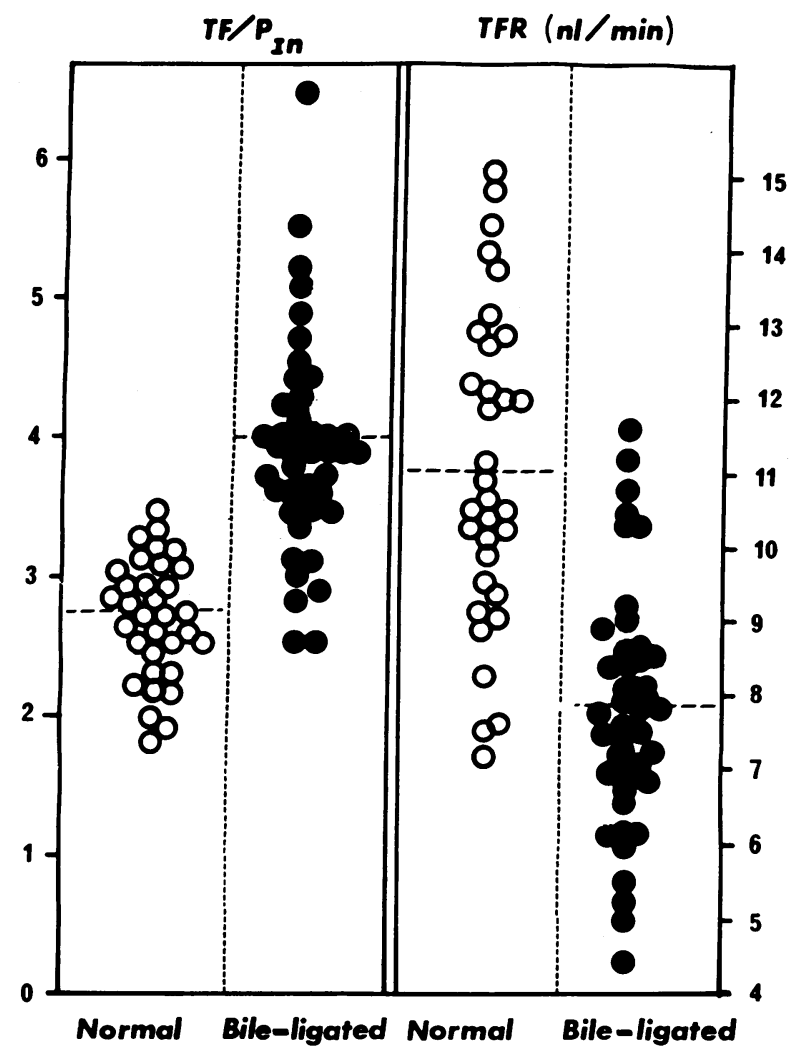

Figure 1 End-proximal $T F / P_{I n}$ and $T F R$ in normal rats and rats with ligation of the common bile duct. 


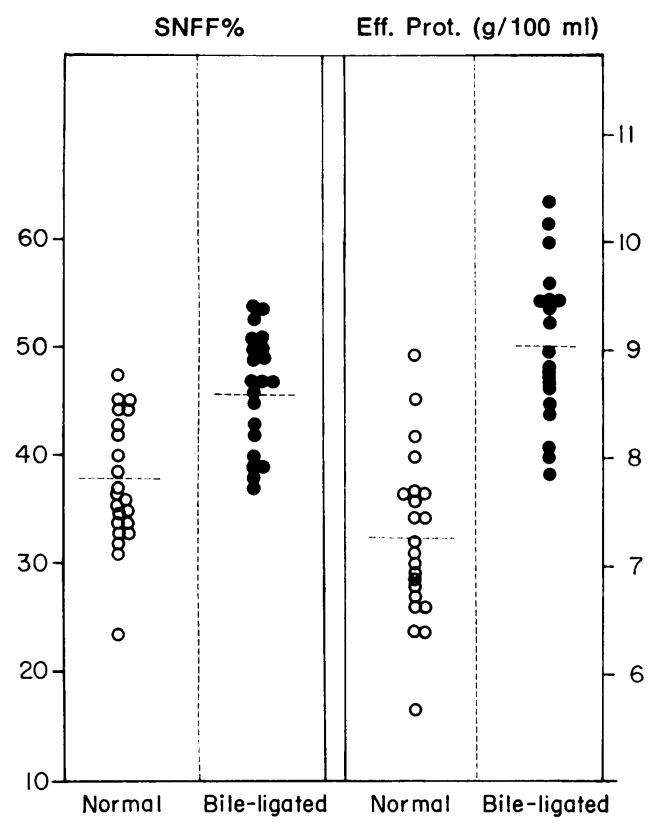

FIGURE 2 SNFF and efferent arteriolar protein concentration in normal rats and rats with ligation of the common bile duct.

ture sites by microdissection. The values ranged from 22.3 to 36.8 with a mean of $27.2 \pm 2.4 \mathrm{SE}$. These are much higher than we have observed for any location along the distal convoluted tubule in normal hydropenic rats (5.8-14) (16).

The mean SNGFR for the control rats was $29.0 \mathrm{nl} /$ min and that for the experimental group was $30.7 \mathrm{nl} / \mathrm{min}$ (Table III). These values are not significantly different from one another. Since the filtered amounts of sodium and water were the same in the two groups of animals, the absolute rate of sodium and water reabsorption by the proximal tubules was increased in the bile ductligated rats.

The data on SNFF and the calculated protein concentration in efferent arteriolar blood are shown in Fig.
2. The mean $\mathrm{SNFF}$ in the control rats was $0.38 \pm 0.01$ $\mathrm{SE}$ and in the experimental rats was $0.46 \pm 0.01 \mathrm{SE}$ $(P<0.001)$. SNFF has been measured by several different methods in normal hydropenic rats, and the results seem to vary considerably according to the method used. We previously reported a value of 0.36 determined by simultaneous measurements of inulin and PAH collected from distal convoluted tubules (10). Brenner, Troy, Daugharty, and McInnes (17) found an average SNFF of 0.27 in hydropenic rats, when calculated from protein concentrations measured in efferent arteriolar and femoral artery blood. A much higher value, 0.47 , was found by Weinman et al. (14) who also measured arterial and efferent arteriolar protein concentration. Brenner and Galla (18) found SNFF to be 0.36 in normal hydropenic rats when calculated from arterial and efferent arteriolar hematocrit measurements. Although the reasons for the variations in results are not clear, we believe that the estimates made from hematocrit measurements are more reliable than those made from protein measurements for two reasons. First, as pointed out by Weinman et al. (14), the Lowry protein method overestimates the true protein value at high concentrations. Secondly, the efferent arteriole may not be entirely impermeable to protein, and some may be lost between the glomerulus and the surface of the kidney where efferent blood samples are obtained. The ultramicro-hematocrit method, on the other hand, is free of this latter theoretical problem and is relatively easy to carry out. Whatever the merits of these various techniques, in the present study a highly significant difference was found in SNFF between the control and bile duct-ligated rats.

It should be noted that in both the control and experimental rats, SNFF was higher than the corresponding whole kidney FF (Table II), the difference in the experimental rats being striking. In other studies in which whole kidney FF was compared with SNFF in normal rats $(10,14)$, the former was measured by

TABLE III

Micropuncture Data in Normal and Bile Duct-Ligated Rats

\begin{tabular}{|c|c|c|c|c|c|c|}
\hline & $\mathrm{TF} / \mathrm{P}_{\mathrm{In}_{\mathbf{n}}}$ & TFR & SNGFR & SNFF & Prote & SNBF \\
\hline & & $n l / \min$ & $n l / m i n$ & $\%$ & $\mathrm{~g} / 100 \mathrm{ml}$ & $n l / \min$ \\
\hline \multicolumn{7}{|c|}{ Normal rats } \\
\hline Mean & $2.69(32)$ & $11.0(32)$ & 29.0 & $38.0(22)$ & 7.27 (22) & $142.5(22)$ \\
\hline$\pm \mathrm{SE}$ & 0.07 & 0.4 & 0.8 & 1.0 & 0.21 & 5.1 \\
\hline \multicolumn{7}{|c|}{ Experimental rats } \\
\hline Mean & $3.96(45)$ & $7.8(45)$ & $30.7(45)$ & $46.0(21)$ & $9.05(21)$ & $112(21)$ \\
\hline$\pm \mathrm{SE}$ & 0.11 & 0.3 & 1.0 & 1.0 & 0.22 & 7.8 \\
\hline$P$ & $<0.001$ & $<0.001$ & NS & $<0.001$ & $<0.001$ & $<0.001$ \\
\hline
\end{tabular}

The numbers in parentheses are the number of observations. 
inulin and para-amino hippuric acid (PAH) clearances, and the two FF's were found to agree with one another closely. However, the assumption that $\mathrm{C}_{\mathbf{P A B}}$ can be equated with effective plasma flow may not be valid. Cortney, Mylle, Lassiter, and Gottschalk (19) found that less PAH appears in the final urine than is present in cortical distal tubules, a finding which we confirmed (10). This might mean that some PAH is reabsorbed in the collecting ducts. If this were so, FF estimated by insulin clearance/PAH clearance would be erroneously high. In the present study, FF was estimated by inulin extraction. Since inulin entering the renal artery is lost from the blood by filtration only, the measurement of inulin extraction is a direct means of estimating FF. The data indicate that in the normal hydropenic rat, the superficial nephrons have a slightly higher FF than the deeper nephrons. In the bile duct-ligated animals, a marked increase in SNFF of superficial nephrons occurred in the absence of any detectable change in whole kidney FF.

As a consequence of the increase in SNFF, the protein concentration in efferent arteriolar blood was significantly higher in the bile duct-ligated rats than in the controls. The mean Prote for normal rats was 7.27 $\mathrm{g} / 100 \mathrm{ml} \pm 0.21 \mathrm{SE}$ and for the experimental rats was $9.05 \mathrm{~g} / 100 \mathrm{ml} \pm 0.22 \mathrm{SE}$. Because there was no difference in the arterial protein concentrations of the two groups of rats, the higher efferent arteriolar protein concentration in the experimental rats was due to the higher SNFF rather than an increase in arterial protein concentration.

The mean SNBF values for the two groups of rats, calculated from eq. 6, are shown in Table III. This equation expresses the blood flow entering the glomerulus from the afferent arteriole. As can be seen, SNBF of the superficial nephrons was significantly lower in the bile duct-ligated rats than in the normal controls. This marked reduction in surface nephron blood flow occurred in the absence of any significant decrease in whole kidney blood flow (Table II).

\section{DISCUSSION}

The results of the present study demonstrate that ligation of the common bile duct in the rat leads to sodium and water retention by the kidney, in the same fashion as has previously been found in dogs (1-3). This experimental model mimics in several respects the renal pathophysiology of patients with intrinsic liver disease. Thus, patients with cirrhosis of the liver may develop renal sodium retention, peripheral edema, and ascites. They also may have impairment of maximum urinary concentration $\left(U_{\max }\right)$ and free-water clearance $\left(\mathrm{C}_{\mathrm{H}_{2} \mathrm{O}}\right)$, with intact ability to reabsorb free-water $\left(\mathrm{T}^{\mathrm{c}} \mathrm{H}_{2} \mathrm{O}\right)$ (4, $5,7)$. Dogs with bile duct ligation demonstrate these same disturbances of renal function (3). It seems rea- sonable to assume, therefore, that the experimental findings of the present study bear upon the renal pathophysiology in patients with liver disease.

Before discussing the micropuncture findings, we wish to call attention to an important problem in these experiments. Because of the presence of ascites, it was possible that the abdominal surgery necessary to collect micropuncture samples might acutely alter renal hemodynamics. It is well known that sudden removal of large amounts of ascitic fluid from patients with liver disease can lead to contraction of intravascular volume, a fall in GFR, and oliguria. Obviously, if such changes were allowed to occur in the experimental animals, the micropuncture observations would reflect the response to acute plasma volume contraction rather than the state of the animal before surgery. Two precautions were taken to avoid this complication. First, animals were studied at an early stage in the development of ascites, 10-14 days after bile duct ligation. We purposely rejected rats that had massive ascites, since it would have been impossible to avoid significant losses of fluid during surgical preparation for micropuncture. Secondly, the abdominal surgery was modified to prevent any loss of ascitic fluid (see Methods). With these precautions, sudden reductions in plasma volume were probably avoided in the experimental rats. Although we cannot be certain that a change in intra-abdominal pressure due to laparotomy did not lead to some intercompartmental shifts of body fluid, the fact that GFR and RBF in the experimental rats were the same as in the normal controls suggests that intravascular volume was not severely reduced.

The micropuncture data indicate that sodium and water reabsorption was markedly increased in the proximal convoluted tubule (Fig. 1, Table III). From the few distal tubular fluid collections, fluid absorption also appeared to be increased in segments beyond the proximal convolutions. Since SNGFR was the same as in the control rats, sodium and water absorption was increased in absolute amounts as well as fractionally. Our observations are in accord with the clearance study of Better and Massry (3) in dogs, and with a micropuncture study by Yarger in rats (20). Yarger found that proximal and early distal $T F / P_{\text {In }}$ ratios were elevated in bile duct-ligated rats (20). Intrarenal blood flow distribution, measured with microspheres, demonstrated decreased fractional flow to the outer cortex and increased fractional flow to the inner cortex. A disproportion between SNGFR and cortical blood flow led Yarger to suggest that FF was increased in superficial nephrons, a suggestion confirmed by the present study. An important difference between his findings and ours is that GFR and SNGFR were significantly lower in his bile duct-ligated animals, compared with controls. 


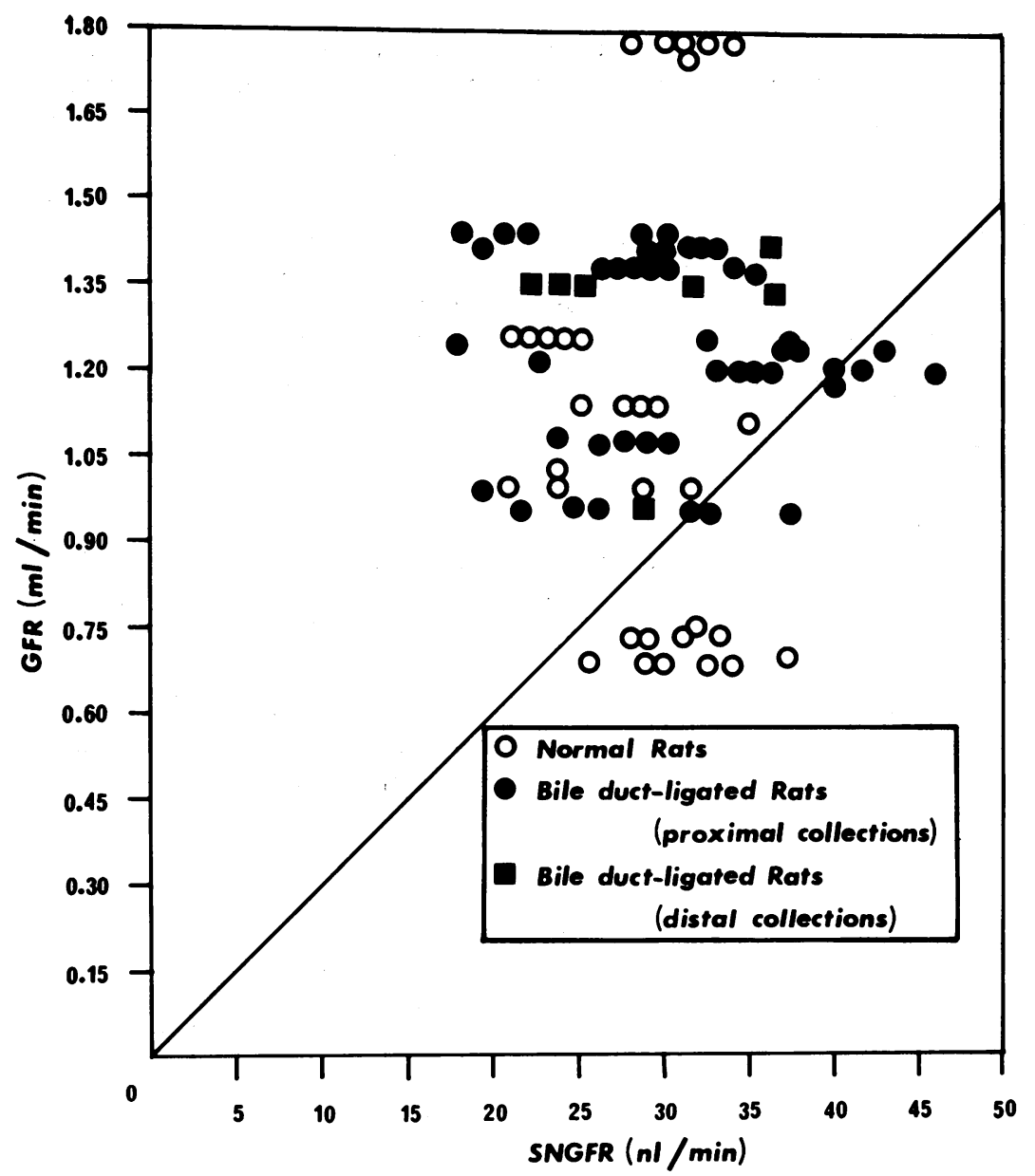

FIGURE 3 Correlation between SNGFR and whole kidney GFR measured simultaneously. The diagonal line indicates the expected GFR if there are 30,000 nephrons in the rat kidney and all nephrons have the same SNGFR.

Since Yarger studied the rats shortly after positive sodium balance began, whereas we studied them 10-14 days after bile duct ligation, it seems reasonable to assume that differences in timing account for the different findings. Thus, in the early stages of sodium retention, reduced filtration rate may contribute to positive sodium balance. As extracellular fluid volume expands, filtration rate may return toward normal, at which time the elevated peritubular protein concentration is responsible for continuing sodium retention. An alternative explanation for the low filtration rates in Yarger's animals is that they were studied soon after an initial period of postoperative sodium loss (20), and therefore may have been somewhat volume contracted.

According to current concepts, sodium retention by the kidney might be due to a decrease in filtered sodium (GFR), high levels of circulating aldosterone, redistribution of the glomerular filtrate to deep nephrons, a decrease in circulating "natriuretic" hormone, or to a change in peritubular physical forces (21). The present study allowed an evaluation of most of these possibilities. It was found that SNGFR and whole kidney GFR were no different than in control rats. Although a reduced filtration rate may have contributed to sodium retention soon after bile duct ligation (20), at this later stage sodium reabsorption was increased in the presence of normal filtration rates. The findings also argue against a redistribution of filtration within the kidney. In order to examine this possibility more closely, individual values for SNGFR were plotted against the simultaneously measured GFR for both groups of rats. The data are shown in Fig. 3. The diagonal line indicates the expected GFR for any given value of SNGFR if there are 30,000 nephrons in the rat kidney and if all nephrons have the same filtration rate. As can be seen from Fig. 3, most of the points for the control rats fall above the line, suggesting that deeper nephrons normally have higher filtration rates than superficial nephrons (22-24). The bile duct-ligated rats show essentially the same pattern as the controls. If redistribution of filtration to 
deep nephrons had occurred, the points would have been shifted toward the left. Thus, there is no evidence to suggest that redistribution of filtration was the mechanism of sodium retention in these animals. Finally, large amounts of $d$-aldosterone were given i.v. to both groups of rats, starting approximately $1 \mathrm{~h}$ before micropuncture collections and continuing throughout the experiment. It seems unlikely, therefore, that differences in circulating aldosterone levels can account for the enhanced proximal and distal sodium and water reabsorption in the bile duct-ligated animals. No experiments were carried out regarding the possibility of a decrease in circulating levels of natriuretic hormone.

The main finding to account for enhanced reabsorption is the markedly higher SNFF in the superficial nephrons of the bile duct-ligated rats. The total protein concentration of the efferent arteriolar blood, calculated from the SNFF and arterial protein concentration, was significantly higher than in the normal control rats (Fig. 2). Since electrophoresis of plasma proteins in both groups of animals yielded approximately the same fraction for albumin, the concentration of efferent arteriolar albumin was presumably also much higher in the experimental than in the normal rats. A considerable body of experimental evidence has demonstrated that acute changes in peritubular oncotic pressure exert an important effect on sodium reabsorption by the proximal convoluted tubule (see reference 21 for review). Although it has not previously been demonstrated that changes in peritubular oncotic pressure can influence sodium balance over long periods of time, the present findings suggest that this was the mechanism for renal sodium retention in this experimental model. Since FF for the whole kidney was not increased in the experimental rats, we assume that renal sodium retention was due to enhanced reabsorption primarily by cortical nephrons, rather than by all of the nephrons. However, since deep nephrons were not examined directly in this study, we cannot exclude the possibility that they also participated in the sodium retention.

A second finding is that SNBF was significantly reduced in the experimental rats, even though there was no reduction in whole kidney blood flow. It seems from these observations that there was relative ischemia of the superficial cortex, and that blood flow to deeper nephrons was either normal or increased. These conclusions are in agreement with the microsphere distribution found by Yarger (20). Cortical ischemia has been diagnosed in patients with cirrhosis of the liver on the basis of renal PAH extraction measurements (25) and xenon washout curves (26). From the present findings that SNGFR was normal while SNBF was reduced, we conclude that cortical ischemia is the result primarily of an increase in efferent arteriolar resistance. The underlying cause of efferent arteriolar vasoconstriction in this experimental model or in patients with liver disease is unknown and obviously requires further investigation.

Several other renal functional disturbances present in animals with bile duct obstruction might be accounted for by the present findings. Impaired $\mathrm{C}_{\mathrm{H}_{2} \mathrm{O}}$, which has been observed in dogs with ligation of the common bile duct (3), might be the result of enhanced reabsorption of fluid in the proximal tubules of cortical nephrons, since $\mathrm{C}_{\mathrm{H}_{2} \mathrm{O}}$ is thought to be the function primarily of cortical nephrons (27). If the delivery of fluid to the distal diluting segment is severely reduced in the cortical nephrons, as was the case in the present experiments, impaired $\mathrm{C}_{\mathrm{H}_{2} \mathrm{O}}$ could result. The loss of normal $U_{\max }$ but preservation of $\mathrm{T}^{\mathbf{c}}{ }_{\mathbf{2}} \mathbf{0}$, findings present in bile duct-ligated dogs (3), might also be explained by the present observations. The fact that SNBF was reduced while RBF was not implies that blood flow to deeper nephrons was higher than normal. Increased medullary blood flow would be expected to diminish the solute concentration of the interstitium under hydropenic conditions, and thus interfere with $U_{\max }$, but not necessarily impair $\mathrm{T}_{\mathrm{H}_{2} \mathrm{O}}^{\mathrm{c}}$ (27). It has been suggested that a similar alteration of intrarenal hemodynamics is responsible for the concentrating defect in patients with cirrhosis of the liver $(5,25)$, but whether elevated peritubular protein concentration is responsible for fluid retention in such patients is unknown.

An important question left unresolved by the present experiments is the sequence of events leading to the disturbance of renal hemodynamics and sodium retention by the kidney. Two main possibilities can be considered. First, it is possible that liver disease results in loss of fluid from the surface of the liver into the abdominal cavity, thereby causing contraction of intravascular volume and secondary renal hemodynamic disturbances. It is of interest that chronic dehydration produced by diuretics and low-salt diet causes an increase in SNFF without a comparable rise in whole kidney FF (14), findings similar to those in the bile ductligated rats. However, volume contraction also led to a marked reduction in GFR (14), which was not observed in the present experimental animals. A second possibility is that neural or hormonal disturbances caused by liver disease are directly responsible for the renal hemodynamic changes. In dogs with constriction of the thoracic inferior vena cava, a pattern of $R B F$ similar to that in patients with liver disease has been observed, i.e., hypoperfusion of the cortex with maintained or increased medullary blood flow (28-30). Studies in such animals have suggested that both the adrenergic nervous system and a humoral factor, possibly renin-angiotensin, are responsible for the cortical ischemia (29). However, Chaimovitz, Massry, Friedler, and Coburn (31) recently reported that renal denervation and $\alpha$-adrenergic blockade with dibenzyline failed to increase urinary sodium excretion or improve the blunted response to 
saline infusion in dogs with chronic bile duct ligation. Whatever the mechanism eventually proves to be, the present study provides evidence that constriction of cortical efferent arterioles occurs in bile duct obstruction, leading to elevation of peritubular protein concentration. To our knowledge, this is the first demonstration that increased peritubular colloid oncotic pressure can account for chronic sodium retention by the kidney.

\section{ACKNOWLEDGMENTS}

The authors are grateful for the excellent technical assistance of Mrs. Cathy Cesario and Mr. Saul Cohen.

This work was supported by U. S. Public Health Service Grant 5 RO1-HL 14720.

\section{REFERENCES}

1. Gliedman, M. L., H. J. Carroll, L. Popowitz, and J. F. Mullane. 1970. An experimental hepatorenal syndrome. Surg. Gynecol. Obst. 131: 34-40.

2. Mullane, J. F., and M. L. Gliedman. 1970. Renal response to saline load in experimental liver disease. $J$. Surg. Res. 10: 519-523.

3. Better, O. S., and S. G. Massry. 1972. Effect of chronic bile duct obstruction on renal handling of salt and water. J. Clin. Invest. 51 : 402-411.

4. Schedl, H. P., and F. C. Bartter. 1960. An explanation for and experimental correction of the abnormal water diuresis in cirrhosis. J. Clin. Invest. 39: 248-261.

5. Jick, H., D. E. Kamm, J. G. Snyder, R. S. Morrison, and T. C. Chalmers. 1964. On the concentrating defect in cirrhosis of the liver. J. Clin. Invest. 43: 258-266.

6. Shear, L., J. Kleinerman, and G. J. Gabuzda. 1965. Renal failure in patients with cirrhosis of the liver. I. Clinical and pathologic characteristics. Am. J. Med. 39: 184-198.

7. Shear, L., P. W. Hall, III, and G. J. Gabuzda. 1965. Renal failure in patients with cirrhosis of the liver. II. Factors influencing maximal urinary flow rate. Am. J. Med. 39: 199-209.

8. Klingler, E. L., Jr., C. A. Vaamonde, L. S. Vaamonde, R. G. Lancestremere, H. J. Morosi, E. Frisch, and S. Papper. 1970. Renal function changes in cirrhosis of the liver. Arch. Intern. Med. 125: 1,010-1,015.

9. Bank, N. 1962. Relationship between electrical and hydrogen ion gradients across rat proximal tubule. $\mathrm{Am}$. J. Physiol. 203: 577-582.

10. Yarger, W. E., H. S. Aynedjian, and N. Bank. 1972. A micropuncture study of postobstructive diuresis in the rat. J. Clin. Invest. 51: 625-637.

11. Windhager, E. E., and G. Giebisch. 1961. Micropuncture study of renal tubular transfer of sodium chloride in the rat. Am. J. Physiol. 200: 581-590.

12. Reinhold, J. G. 1953. Total protein, albumin, and globulin. In Standard Methods of Clinical Chemistry. M. Reiner, editor. Academic Press Inc., N. Y. 1: 88-97.

13. Powell, L. W., M. A. Dunnicliff, and B. H. Billing. 1968. Red cell survival in experimental cholestatic jaundice. Br. J. Haematol. 15: 429-435.

14. Weinman, E. J., M. Kashgarian, and J. P. Hayslett. 1971. Role of peritubular protein concentration in sodium reabsorption. Am. J. Physiol. 221: 1521-1528.

15. Glabman, S., H. S. Aynedjian, and N. Bank. 1965. Micropuncture study of the effect of acute reductions in glomerular filtration rate on sodium and water reab- sorption by the proximal tubules of the rat. J. Clin. Invest. 44 : 1410-1416.

16. Bank, N., and H. S. Aynedjian. 1973. A micropuncture study of potassium excretion by the remnant kidney. J. Clin. Invest. 52 1480-1490.

17. Brenner, B. M., J. L. Troy, T. M. Daugharty, and R M. MacInnes. 1973. Quantitative importance of changes in postglomerular colloid osmotic pressure in mediating glomerulotubular balance in the rat. J. Clin. Invest. 52: 190-197.

18. Brenner, B. M., and J. H. Galla. 1971. Influence of postglomerular hematocrit and protein concentration on rat nephron fluid transfer. Am. J. Physiol. 220: 148-161.

19. Cortney, M. A., M. Mylle, W. E. Lassiter, and C. W. Gottschalk. 1965. Renal tubular transport of water, solute, and PAH in rats loaded with isotonic saline. $\mathrm{Am}$. J. Physiol. 209: 1199-1205.

20. Yarger, W. E. 1974. A micropuncture study of salt retention associated with bile duct ligation (BDL) in rats. Clin. Res. 22 : $551 a$.

21. Schrier, R. W., and H. E. DeWardener. 1971. Tubular reabsorption of sodium ion: influence of factors other than aldosterone and glomerular filtration rate. N. Engl. J. Med. 285: 1231-1243, 1292-1303.

22. Horster, M., and K. Thurau. 1968. Micropuncture studies on the filtration rate of single superficial and juxtamedullary glomeruli in the rat kidney. Pfluegers Arch. Eur. J. Physiol. 301 : 162-181.

23. Stumpe, K. O., H. D. Lowitz, and B. Ochwadt. 1969. Function of juxtamedullary nephrons in normotensive and chronically hypertensive rats. Pfuegers Arch. Eur. J. Physiol. 313: 43-52.

24. Jamison, R. L. 1970. Micropuncture study of superficial and juxtamedullary nephrons in the rat. Am. J. Physiol. 218: 46-55.

25. Schroeder, E. T., L. Shear, S. M. Sancetta, and G. J. Gabuzda. 1967. Renal failure in patients with cirrhosis of the liver. III. Evalution of intrarenal blood flow by $\mathrm{PAH}$ extraction and response to angiotensin. Am. J. Med. 43: 887-896.

26. Epstein, M., D. P. Berk, N. K. Hollenberg, D. F. Adams, T. C. Chalmers, H. L. Abrams, and J. P. Merrill. 1970. Renal failure in the patient with cirrhosis. The role of active vasoconstriction. Am. J. Med. 49: 175-185.

27. Seldin, D. W., G. Eknoyan, W. N. Suki, and F. C. Rector, Jr. 1966. Localization of diuretic action from the pattern of water and electrolyte excretion. Ann. N. Y. Acad. Sci. 139: 328-343.

28. Kilcoyne, M. M., and P. J. Cannon. 1971. Influence of thoracic caval occlusion on intrarenal blood flow distribution and sodium excretion. Am. J. Physiol. 220: 1220-1230.

29. Kilcoyne, M. M., and P. J. Cannon. 1971. Neural and humoral influences on intrarenal blood flow distribution during thoracic caval occlusion. Am. J. Physiol. 220: 1231-1237.

30. Newsome, H. H., Jr., M. S. Kafka, and F. C. Bartter. 1971. Intrarenal blood flow in dogs with constriction of the inferior thoracic vena cava. Am. J. Physiol. 221: 48-52.

31. Chaimovitz, C., S. G. Massry, R. M. Friedler, and J. W. Coburn. 1974. Effect of renal denervation and $\alpha$ adrenergic blockade on sodium excretion in dogs with chronic ligation of the common bile duct. Proc. Soc. Exp. Biol. Med. 146: 764-770. 